\title{
Telling tales: students' learning stories
}

\author{
Dr Karen Fitzgibbon \\ University of Glamorgan, UK \\ Dr Jacqueline Harrett \\ University of Glamorgan, UK
}

\begin{abstract}
This paper outlines research conducted with undergraduate students. By listening to students' learning experiences the authors were able to support them and develop ways to enable them to become more effective learners. Sharing their learning stories helped students establish a sense of community as they realised the commonality of many experiences. Reflection on learning also helped them to resolve issues from the past and move forward in a more positive spirit. Through talking and telling, thinking and reflecting, the student voice becomes more audible and the tutor/student relationship more conducive to successful learning.
\end{abstract}

Keywords: learning; reflection; sharing; stories; experiences.

\section{Introduction}

The literature concerning the use of storytelling for learning is rich and diverse. The influences in this area include Egan (1989), Zipes (1996), Winston (1997) Grugeon and Garder (2000), and Cremin (2009), among others, who believe in the power of story to engage children in meaningful learning. The use of storytelling in higher education is given specific attention by Alterio and McDrury (2003), Barrett (2006) and Moon (2010).

The research described in this paper was prompted by discussions between the authors during a sandpit research event. By having an opportunity to converse with others we discovered that we had both been investigating the same topic, albeit from different 
angles. The common thread was student narratives of their learning experiences and, by pooling knowledge and interest, we decided to further investigate the nature of student learning narratives and how those past experiences affect and influence future development.

The context for this research is a post-92 university located in the South Wales Valleys with a population of approximately 23,000 students, $70 \%$ of who are studying for undergraduate degrees. Many students are the first in their families to experience higher education and as such are drawn from non-academic backgrounds where university life may be outside their experiences and those of friends and family.

Student life can be challenging in many respects and affected by previous learning experiences. Support for students may be practical, or pastoral, but listening actively to student learning experiences requires what Maguire (1998, p.18) describes as the 'ongoing consideration of the listener'. In other words, listening and responding appropriately. This active listening may be the role of the peer group or individuals, such as a tutor. Maguire insists that personal storytelling helps others to engage with those experiences. This research had a focus on student learning narratives and how sharing these stories may lead to reflection and understanding, both personal and in the wider community.

Sharing learning journeys provides students with many benefits: they are able to relate to each other in more open ways; they develop more confidence in articulating perceived successes and failures; they may help to place experiences into a wider perspective; and they provide the tutor with additional knowledge about the needs and expectations of the students in their care. This research considered how tutor knowledge of their students, as well as the student experience, was enhanced by the sharing of learning stories. By sharing stories, both tutors and students were able to identify common experiences and understand how, despite changes in society and the rise in the use of technology, the human condition remains much the same. This mutual understanding allowed both students and tutors to have more insight into the personalities and personal lives of others. For example, tutors realised that although the students in the classes were classed as adults, they were perhaps not as 'grown up' or sophisticated as they seemed. One eighteen year old recalled how going on holiday with friends, not parents, just before university had been difficult, and many students expressed apprehension about leaving home and the security of family life. This reminded tutors of Maslow's (1954) hierarchy of 
needs and the importance of the pastoral role. It enabled tutors to provide guidance and support and perhaps to be more sensitive to the needs of these young adults.

\section{Methods}

As a pilot intervention, first year students studying Early Years Education were introduced to the idea of telling their stories by the concept of a memory box, where articles symbolising experiences were placed in a box. Memory boxes usually contain keepsakes of some sort, possibly insignificant articles which hold some sentimental value. Some museums also provide memory boxes as learning resources for schools so that children may see, through the handling of objects, what life may have been like for people in other centuries. The students were shown a photograph of a child's memory box and how the items in the box were significant to the child's self-esteem, relationships, and also learning about life. The students were then provided with a simple grid on which to note their learning stories.

Tutors shared their own learning memories with the group, emphasising learning in wider contexts than school or university and quoting a variety of experiences which were 'learning experiences'. This openness was designed to give the students confidence and provide what Garnett (2005, p.153) described as a 'collaborative exercise' to build positive relationships. Tutors described which objects they would include in a memory box to demonstrate the connection between objects and memories of learning experiences. Students were then given the opportunity to talk in small groups and share thoughts and ideas before telling their stories to a larger group if they wished.

It should be noted that the first year cohort on this particular course is a large group with over 120 students. The students we worked with were in two groups of 43 and 36 respectively - the students present at the lecture times we had designated for the data gathering. 'Fresher's flu' and other seasonal illnesses at the time resulted in poor attendance at some sessions so the students 'chosen' were those who were present at the time. Students could easily be intimidated by the large group setting so it was imperative that they felt comfortable in talking to friends and then to the whole class, if they felt confident enough. It was noted at the time that one group was more lively and talkative than the other so the dynamics of the personalities involved may have had an effect on the 
overall variables of the discussions. We have observed that often when some students are willing to start discussions, others will follow the lead and become involved. Some groups are naturally more vivacious and loquacious which could have led to more animated and revealing narratives. It is also possible that hearing other students respond to the tutors' stories increased the confidence of the quieter members of the group such that they felt enabled to participate.

Following talking and telling, thinking and reflecting, students were asked to record significant events in their learning journeys on a simple grid. They identified an object which they associated with a learning event, such as car keys to signify passing the driving test, and wrote a short description noting whether it was a negative or positive learning experience.

A small number of students from the cohort then volunteered to be interviewed, using a semi-structured interview schedule. This was a mixture of self-selected students and others who were asked if they would mind being interviewed as they had shared stories which demonstrated personal learning. We thought this mixture of participants should provide an interesting and eclectic source of information. They were questioned about a positive learning experience and a negative one and asked to elaborate and reflect on these experiences. Grainger (2005) deliberates on this dialogic process as a means of cognition and inter-thinking, believing that making connections in this way provides more motivation for learners. The interviews provided a rich data source which requires further analysis and will be presented in future work. The results discussed in this paper are from the analysis of the learning grids used with each group.

Initial tentative data analysis from the pilot group enabled us to reflect on the themes which appeared to be emerging. As Silverman (2009) suggested this early data analysis was a useful process in enabling us to see the possible direction of the research. We modified the grid to contain an easily identifiable column for the students to indicate whether the experience was positive or negative and we then proceeded to use the modified grid to gather data from the second and third year students. A maximum number of five experiences could be entered into the grid. Some students recorded just one, while others filled all five boxes. 
Figure 1. Modified grid used to record student experiences.

\section{LEARNING BOXES}

\begin{tabular}{|l|l|l|}
\hline Item & Positive or & Reason for choice (story) \\
negative & \\
learning & \\
experience & \\
\hline & & \\
\hline & & \\
\hline & & \\
\hline & & \\
\hline & & \\
\hline
\end{tabular}

\section{Results and analysis}

\section{Data from the pilot phase - year one students}

Students had been introduced to Claxton's 4Rs (2002) theory in the discussions prior to completing the grid. Claxton believes that certain aspects are essential to effective learning. The $4 \mathrm{Rs}$ refer to resilience, the ability to keep on trying even when learning is difficult; resourcefulness, knowing of different ways to approach learning; reflection, an ability to evaluate learning; and relationships, where learning in groups or individually may be important. We also discussed the importance of the teacher/pupil relationship as most adults had experience of a teacher that they either loathed or loved. Some students made choices of subjects to study on the basis of those relationships. These themes of resilience, resourcefulness, reflection and relationships were mirrored to some extent in responses. Responses were categorised into negative, positive or mixed experiences as shown in Table 1. 
Table 1. Summary of positive, negative and mixed experiences for year one students - the pilot group.

\begin{tabular}{|l|l|l|l|}
\hline Age group & Positive & Negative & Mixed \\
\hline $18-21$ & 197 & 23 & 49 \\
\hline $21-30$ & 23 & 12 & 12 \\
\hline $30-40$ & 9 & 0 & 1 \\
\hline
\end{tabular}

Mixed responses were positive experiences which had later become negative or negative experiences which became positive and some of the aspects of Claxton's theory were apparent. These mixed responses depended on student reflection on the nature of the learning experience and what they had learnt overall from that experience. For example, for a negative experience to have changed to positive usually required reflection, resilience and possibly resourcefulness in the face of adversity. A number of the responses also mentioned a significant person who had been a strong influence, either negative or positive, on their attitude to learning, indicating that relationships were important in the learning process and in developing attitudes to learning.

Other themes became apparent in identifying what types of learning experiences were common to the groups. These were broadly placed in three streams: academic, recreational and life experiences. As may be expected, there was a commonality of experience, and things like exam results, learning to drive and achieving independence through moving to university had predominance. Following from this pilot we continued the research with both year two and year three groups. Our aims were to discover if building these positive and open relationships had any impact on retention of students, as we had a significant 'drop-out' rate between years. We hoped that by learning and reflecting together on shared learning experiences we could produce a more collegial environment where students could feel less isolated. An atmosphere of mutual respect where both tutor and student voices could be heard and recognised as valued was regarded as important.

We had no formal method of measuring the impact of this exercise, although we charted the common threads and themes as may be seen later in this paper. The theory of 'communities of practice' put forward by Lave and Wenger in 1991 has been expanded in Wenger et al.'s (2011) research. He has developed the theory of social learning encompassing both communities and networks of learners, which are regarded as 
complementary. The interplay between communities and networks of learners is possibly blurred in university groups as students access their learning from different sources. The ability to utilise blended learning, through lectures, seminars and from the virtual learning environment may have positive and negative effects. With more and more use of technology to communicate there may be less opportunity for students to participate in face-to-face social learning and sharing of experiences. Our research aimed to enable students to form a sense of mutual trust and respect through their shared narratives.

\section{Data from the main phase - year two students}

After piloting the learning grids with the year one students, the topic was introduced with year two students as part of the session on writing across the curriculum. We explained about memory boxes and the work of Claxton in this context and took a box with personal items which we used as metaphors for learning in our own experiences. The second year group consists of 29 students and represented a mix of ages but all the students were female. In total, the group generated 122 learning experiences which they shared on their grids as Table 2 shows.

Table 2. Summary of positive, negative and mixed experiences for year two students.

\begin{tabular}{|l|l|l|l|}
\hline Age group & Positive & Negative & Mixed \\
\hline $18-21$ & 38 & 12 & 19 \\
\hline $21-30$ & 20 & 4 & 16 \\
\hline $30-40$ & 10 & 2 & 1 \\
\hline
\end{tabular}

The second year group was very responsive and immediately began to discuss in small groups their chosen learning stories. There was much excited and animated discussion and also some thoughtful reflection. Whilst students had worked together for some time, it became apparent that the sharing of stories about happy, funny and sometimes quite painful and difficult events, was something they willingly participated in. 


\section{Year three}

The introduction to the topic was slightly different with year three students as they had been exposed to the idea of memory boxes the previous year so just needed a brief reminder. This particular session began with a questionnaire about learning which was used as a basis for discussion on what was needed in the curriculum in the $21^{\text {st }}$ century. They discussed topics like: 'Where does learning take place?'; 'How do you learn best?'; and 'What is successful learning?'. Reference to Robinson's (2006) celebrated speech on TED was made and also to prior work on learning and their own memories about learning. This was as a precursor to completing the grids with their positive and negative learning experiences. Students then had time to discuss their thoughts and experiences in small groups before whole class sharing. This was a small group of 28 students, with only one male in the group, who were familiar with each other and the tutor, so it was relaxed and open.

It was interesting to note that these students were equally positive when compared with the second year group in their discussions. With their university study near to its conclusion, and the stress of numerous assignments and examinations looming, our expectations for this group were that they would record more negative thoughts and emotions in their learning journeys. As may be seen in Table 3 below, the 21-30 year group seems to be the most positive about their learning, in comparison with the year two cohort where the most positive learners were in the 18-21 age group. A total of 104 learning experiences were recorded on the grids for this third year cohort.

Table 3. Summary of positive, negative and mixed experiences for year three students.

\begin{tabular}{|l|l|l|l|}
\hline Age group & Positive & Negative & Mixed \\
\hline $18-21$ & 19 & 15 & 1 \\
\hline $21-30$ & 46 & 12 & 8 \\
\hline $30-40$ & 3 & 0 & 0 \\
\hline
\end{tabular}

\section{Experiences shared by year two and three students}

Students were very open in their disclosures. One mature student spoke quite openly about her trauma when she discovered she was pregnant at eighteen: 
There I was about to sit my A levels and all ready to go to university and I had this little baby and I just freaked. I thought, 'Oh my God!'. He was so small and dependent on me but he's just great now and I wouldn't be without him and I've learnt so much from that.

The first trawl of the data revealed a commonality of experience which we grouped into three strands - academic experiences, recreational experience and general life experiences. Academic life included experiences, such as tests, examinations or other memories related to school or university learning. Table 4 shows the numbers in each of the second and third year groups who chose to share learning experiences of an academic nature.

Table 4. Academic theme.

\begin{tabular}{|l|l|l|l|l|l|l|l|l|}
\hline Age Group & \multicolumn{2}{l|}{ Positive } & \multicolumn{2}{l|}{ Negative } & \multicolumn{2}{l|}{$\begin{array}{l}\text { Negative into } \\
\text { positive }\end{array}$} & \multicolumn{2}{l|}{$\begin{array}{l}\text { Positive into } \\
\text { negative }\end{array}$} \\
\hline & Year 2 & Year 3 & Year 2 & Year 3 & Year 2 & Year 3 & Year 2 & Year 3 \\
\hline $18-21$ & 10 & 9 & 2 & 3 & 5 & 1 & 0 & 0 \\
\hline $21-30$ & 4 & 14 & 1 & 6 & 5 & 0 & 0 & 0 \\
\hline $30-40$ & 2 & 2 & 2 & 0 & 1 & 0 & 0 & 0 \\
\hline
\end{tabular}

Examples of students' comments included reflecting on early school years, such as this student who wrote:

I won a writing competition in school and it was a big deal in my school. The trophy always reminds me of the excitement, pride and top of the world feeling of that moment and it always makes me smile.

Another student wrote about her exchange year to a university in Florida, demonstrating some of the complexity involved in the reflections:

This experience made me improve my independence as a person and I have learned different techniques from a different culture. 
The second strand was recreation - sports, music, and driving featured strongly. We also included socialising and Duke of Edinburgh Award which featured in a few responses.

Table 5. Recreational theme.

\begin{tabular}{|l|l|l|l|l|l|l|l|l|}
\hline Age Group & \multicolumn{2}{l|}{ Positive } & \multicolumn{2}{l|}{ Negative } & \multicolumn{2}{l|}{$\begin{array}{l}\text { Negative into } \\
\text { positive }\end{array}$} & \multicolumn{2}{l|}{$\begin{array}{l}\text { Positive into } \\
\text { negative }\end{array}$} \\
\hline & Year 2 & Year 3 & Year 2 & Year 3 & Year 2 & Year 3 & Year 2 & Year 3 \\
\hline $18-21$ & 14 & 13 & 6 & 3 & 5 & 1 & 2 & 0 \\
\hline $21-30$ & 6 & 15 & 1 & 2 & 5 & 3 & 1 & 1 \\
\hline $30-40$ & 2 & 1 & 2 & 0 & 1 & 0 & 0 & 0 \\
\hline
\end{tabular}

Some unexpectedly dramatic stories emerged from recreational learning, such as this example from a year two student:

I learned to swim when I was about 5 years old and I am glad my mum took me for lessons, not only because I enjoyed it but because I've helped save someone who was drowning.

Other recreational activities led to developing strength of character as this student showed:

Duke of Edinburgh Gold Award. Completed 50 mile walk. Went to hospital half way through, was told I couldn't carry on but with determination I did it.

The last strand, life experiences, encompassed a number of varying topics such as independence, travel, relationships, births and deaths, and work. It was quite surprising that life experiences did not feature in the responses of the most mature students in the third year group. 
Table 6. Life theme.

\begin{tabular}{|l|l|l|l|l|l|l|l|l|}
\hline Age Group & \multicolumn{2}{l|}{ Positive } & \multicolumn{2}{l|}{ Negative } & \multicolumn{2}{l|}{$\begin{array}{l}\text { Negative into } \\
\text { positive }\end{array}$} & \multicolumn{2}{l|}{$\begin{array}{l}\text { Positive into } \\
\text { negative }\end{array}$} \\
\hline & Year 2 & Year 3 & Year 2 & Year 3 & Year 2 & Year 3 & Year 2 & Year 3 \\
\hline $18-21$ & 14 & 7 & 4 & 0 & 7 & 0 & 1 & 0 \\
\hline $21-30$ & 10 & 11 & 2 & 4 & 3 & 4 & 2 & 2 \\
\hline $30-40$ & 6 & 0 & 0 & 0 & 0 & 0 & 0 & 0 \\
\hline
\end{tabular}

The student narratives in the life theme included some reflections about very difficult experiences:

Domestic violence from my ex made me very unconfident and nervous around men. Now realize it was a bad experience but I am a different person now!

The sharing of such powerful experiences demonstrates the extent to which the students felt comfortable in the safe space created by the tutors, perhaps even more surprising when considering that one of the tutors had not previously met the groups. It was felt that the students responded to the openness and honesty with which the tutors shared their own learning stories. Such reflection clearly helped to achieve one of the aims of the sessions - enabling students to learn and reflect together on shared learning experiences. This provided a supportive and relaxed environment where mutual respect was evident by the active listening patterns of the group and was regarded as valuable to the student learning experience. As Wenger et al. (2011, p.21) comment, 'not all the value produced by a community or a network is immediately realised. Activities and interactions can produce knowledge capital whose value lies in its potential to be realised later'. They maintain that this knowledge capital has an intrinsic value even if it is never realised and that sometimes the knowledge capital may be transferred to 'learning capital'. McDrury and Alterio (2003, p.8) acknowledge the power of storytelling as a learning tool in higher education, particularly the ease with which it can be transferred across disciplines 'to stimulate students' critical thinking skills, encourage self-review and convey practice realities'.

Although some of the comments were insightful it was often the negative into positive experiences which were most interesting. After a car crash one student wrote: 
I am now a very nervous passenger. I have reduced my speed by a lot. I am now aware how quickly and how serious a car crash can be. Life is too short so I think a lot more now.

She has displayed both reflection and resilience in these comments, as did another student with a similar experience:

Someone crashed in to me and wrote off my car. I had trouble with my insurance company and had to get a solicitor so this taught me independence and to stand my ground.

In addition to investigating these strands of common experiences we also explored the nature of the relationships that were accounted for in student narratives. Half the students (14 in total) in the third year cohort mentioned people who were influential in their learning journeys, thus highlighting the importance of relationships. Of these particular experiences nearly half (10 out of 21) were dependent on a close family member such as parent or grandparent. Twenty-one out of 29 second year students mentioned other people as influential in their learning.

One student learnt of her grandmother's illness on her $21^{\text {st }}$ birthday and had to learn resilience in being able to come to terms with her emotions:

I found out that my grandmother had cancer that was terminal and she was the first close person to me that I had to deal with dying.

Another student with a two year old described how this experience had been a totally different and positive influence on her life:

Having a child has been the biggest and best learning experience I will ever go through. It was life changing and even though it's hard work with uni and work I can't imagine life without him. Everything I'm doing is for him and it makes me more determined. 
Through reflection she has learnt resilience, resourcefulness and the importance of relationships is central to her world.

The importance of the teacher/pupil relationship was highlighted by being mentioned seven times as fundamental in a learning experience. Four of these experiences were negative and student learning narratives recorded residual feelings relating to them:

I've hated maths since primary school and was told I was useless at it which has totally put me off. Even now I dread adding up and would be happy never to do maths again.

It is quite startling to acknowledge that a teacher could have such a negative influence on a young person's life over ten years later.

\section{Conclusions}

Contact for young people these days is often through technology where social networking sites provide a 'changed communication paradigm' (Walsh, 2008, p.102). Giving them the chance to interact and 'recognising that learners are in a social context creating knowledge as part of doing things with others' (Watkins, 2003, p.38) provided them with the opportunity to think more deeply about their learning journeys. They were able to reflect on their experiences and expectations and evaluate these retrospectively.

As a result of this collaboration and communication with students we were able to perceive many benefits. In large student cohorts there was often anonymity. Friends formed small social groups within the larger group and did not even know the names of those outside their social framework. Communicating learning stories, especially those which represented difficulty or failure, enabled students to see the commonality of learning experiences, both from tutors and fellow students. Listening actively to personal stories provided empathy in the group as many of these stories were bound in emotions. We learnt more about each other as people and so were able to create a more supportive and less anonymous learning environment. Holmes (2005) asserts that it is usually emotional aspects of well-being which can limit attitudes towards learning. We found that enabling students to tell their tales provided an emotional and cognitive experience on which to 
build future learning and teaching. We have been able to share this research data with colleagues across the university and some of these ideas have been incorporated into cohort group sessions designed to retain students and provide them with a secure pastoral network, both from fellow students and members of the academic staff. The first year group involved in the pilot study is now in the final year of study and these students are open and honest in their evaluations of the course and their requirements. They are vocal in discussions and able to voice opinions, as well as listen attentively to others and respond appropriately. They have more engagement in their learning which Hargreaves (2004) regards as important and they have developed a more reflective attitude towards their work. This may be due to maturity but we hope that our telling of tales and setting the foundations early in their student lives accelerated the process.

\section{References}

Alterio, M. and McDrury, J. (2003) Learning through storytelling in higher education: using reflection and experience to improve learning. London: Routledge.

Barrett, H. (2006) 'Researching and evaluating digital storytelling as a deep learning tool', Society for Information Technology and Teacher Education Conference. Orlando, FL 20-24 March [Online]. Available at:

http://electronicportfolios.org/portfolios/SITEStorytelling2006.pdf (Accessed: 12 December 2011).

Claxton, G (2002) Building Learning Power: Helping Young People Become Better Learners Bristol: TLO Ltd

Cremin, T. (2009) Teaching English creatively. London: Routledge.

Egan, K. (1989) Teaching as storytelling. USA: University of Chicago Press.

Garnett, S. (2005) Using brainpower in the classroom. London: Routledge.

Grainger, T. (2005) 'Oral artistry: storytelling and drama', in Wilson, A. (ed.) Creativity in primary education. Exeter: Learning Matters, pp. 33-43 
Grugeon, E. and Garder, P. (2000) The art of storytelling for teachers and pupils: using stories to develop literacy in primary classrooms. London: David Fulton Publishers.

Holmes, E. (2005) Teacher well-being: looking after yourself and your career in the classroom. London: Routledge.

Hargreaves D. H. (2004) Learning for Life: The Foundations of Lifelong Learning London: Policy Press

Lave, J. and Wenger, E. (1991) Communities of practice: learning, meaning and identity. Cambridge: Cambridge University Press.

Maguire, J. (1998) The power of personal storytelling. New York: Jeremy P.Tarcher/Putnam.

Maslow, A. (1954) Motivation and personality. Harper and Row: New York.

Moon, J.A. (2010) Using story: in higher education and professional development. London: Routledge.

Robinson (2006) 'Schools kill creativity' online at http://www.ted.com/talks/ken_robinson_says_schools_kill_creativity.html Last accessed (8/3/2012)

Silverman D.(2009) Doing Qualitative Research (3rd Edition) London: Sage Publications

Walsh, M. (2008) 'Worlds have collided and modes have merged: classroom evidence of changed literacy practices', Literacy, 42(2), pp. 101-108.

Watkins, C. (2003) Learning: a sense-makers guide. London: ATL.

Wenger, E., Traynor, B. and de Laat, M. (2011) Promoting and assessing value creation in communities and networks; a conceptual framework. Netherlands: Ruud de Moor Centrum. Available at: http://wenger- 
trayner.com/documents/Wenger Trayner DeLaat Value creation.pdf (Accessed: 4 January 2012).

Winston, J. (1997) Drama, narrative and moral education. London: Routledge.

Zipes, J (1996) Creative storytelling: building communities/changing lives. London: Routledge.

\section{Author details}

Dr Karen Fitzgibbon is Head of Educational Development in the Centre for Excellence in Learning and Teaching at the University of Glamorgan. She has worked in the university for many years in both business and education disciplines. Her research interests are the student experience, student retention, online learning, and reflective practice.

Dr Jacqueline Harrett is a Senior Lecturer at the University of Glamorgan. She teaches on the Education courses within the Faculty of Humanities and Social Sciences. She has extensive and varied experience of teaching both in schools and in higher education. Her research interests are in early years and literacy (particularly storytelling). 